\title{
Responses to facial and non-facial stimuli presented tachistoscopically in either or both visual fields by patients with the Capgras delusion and paranoid schizophrenics
}

\author{
Hadyn D Ellis, Karel W de Pauw, George N Christodoulou, Lambis Papageorgiou, \\ Alan B Milne, Anthony B Joseph
}

\begin{abstract}
An experiment was carried out designed primarily to test A B Joseph's suggestion that patients with Capgras delusion may have problems integrating information between the two cortical hemispheres; and at the same time it was meant to examine J Cutting's ideas linking schizophrenia in general, and the Capgras delusion in particular, to right hemisphere dysfunction. Three patients with the Capgras delusion and three matched controls diagnosed as paranoid schizophrenics were briefly presented pairs of line-drawn object and photographs of faces randomly in the left visual field, the right visual field or bilaterally. The results with objects revealed no particular pattern of performance for either group; but, when faces were shown, the controls revealed the usual left visual field/right hemisphere advantage while for the Capgras group this was reversed. The results are not consistent with a simple prediction from Joseph's hypothesis but they are in accord with Cutting's theory-though they also pose some problems for it, which are discussed.
\end{abstract}

(F Neurol Neurosurg Psychiatry 1993;56:215-219)

School of Psychology, University of Wales College of Cardiff, Cardiff CF1 3YG, UK

$\mathrm{H}$ D Ellis

A B Milne

Department of

Psychiatry, Doncaster

Royal Infirmary, UK

KW de Pauw

Psychiatry

Department, Athens

University, Greece

G N Christodoulou

L Papageorgiou

McLean Hospital,

Harvard Medical

School, Belmont, MA,

USA

A B Joseph

Correspondence to:

Professor $\mathrm{H}$ D Ellis

Received 24 October 1991

and in revised form

10 February 1992.

Accepted 25 March 1992 designed to extend other work aimed at exploring neuropsychological techniques for evaluating DMI. ${ }^{1314}$ More properly this approach, perhaps, should be termed cognitive neuropsychiatry. ${ }^{15}$

This experiment was designed to investigate any anomalies of functional cerebral asymmetry in patients with the Capgras delusion compared with paranoid schizophrenics matched by age and sex. It is the first attempt empirically to examine whether, as some have recently proposed, there is any unusual pattern of transcallosal information transfer in Capgras patients; ${ }^{8}$ or whether there is, instead, a dysfunction in right hemisphere functioning. ${ }^{16}$

Joseph $^{8}$ suggested that the Capgras delusion may result from the absence of integration between the left and right cerebral hemispheres which could give rise to the central representation of two facial "images", one in each hemisphere, that are not "fused" and, thus, produce delusions of doubles. This theory implies that Capgras patients may reveal particular problems in making decisions when pairs of faces are presented initially one to each hemisphere rather than both occurring in one hemisphere. Joseph's position makes no prediction regarding non-facial stimuli.

Yet another suggestion was made more recently by Cutting ${ }^{16}$ as part of his general thesis linking right cerebral disorder and psychotic illness. Cutting bases his theoretical position on Kosslyn's ${ }^{17}$ suggestion that the left hemisphere specialises in categorical perception and the right hemisphere in determining variations within a category. According to Cutting, in common with reduplicative paramnesia, the Capgras delusion involves a failure to recognise the uniqueness of a percept because of impairment within the right hemisphere. Patients with delusions regarding people being substitutes may not reveal the usual right hemisphere advantage for face processing ${ }^{18} 19$ but be unaffected in deciding whether two objects from different categories are similar.

In the following experiment the ideas of Joseph $^{8}$ and Cutting ${ }^{16}$ were explored by briefly presenting pairs of drawings of objects and pictures of faces to either one or both hemispheres and requiring a rapid decision on whether the stimuli were the same or different. The technique used capitalises on the crossed 
anatomic arrangement between retinae and cortices. Stimuli falling in the left visual field (LVF) are relayed initially to the right hemisphere ( $R H)$; those occurring in the right visual field (RVF) initially arrive at the left hemisphere (LH). Thereafter information passes rapidly between the cerebral hemispheres via the major commissures.

\section{Method \\ Subjects \\ Informed consent to take part in the experi- ment was given by three Greek male out- patients with a history of the Capgras delusion, and three men diagnosed as paranoid schizo- phrenic acted as controls. Each control patient was matched by sex, age and socio-economic background to one of the Capgras patients. All patients were diagnosed by one psychiatrist (GNC). They form part of the cohort of patients with Capgras delusion and other psychotic symptoms studied by him and his team over a long period. Table 1 summarises the clinical details of each patient in both groups.}

\section{Design and procedure}

For this experiment, pairs of faces and pairs of line drawings of common objects were briefly presented on a computer screen. On each trial the subject was asked to decide as quickly as possible whether the stimuli were the same (that is, identical) or different. Every subject performed one test with line drawings of common objects taken from Snodgrass and Vanderwart; ${ }^{20}$ and another test where pairs of monochrome adult male faces were the stimuli (fig 1). All stimuli were digitised and stored on a Macintosh computer. Programs were written to enable each pair of stimuli to be presented one above the other left or right of a central fixation point (unilateral conditions) or on each side of it (bilateral condition). The stimuli always appeared, phenomenologically, instantaneous but in fact took $16 \mathrm{~ms}$ to become established.

On each trial the subject's task was to fixate a small central cross. Then the stimuli were exposed for $200 \mathrm{~ms}$, which is the maximum duration before eye movements may occur, and the subject was required to press one keyboard button for the decision "same" and another for the decision "different". Practice trials were given beforehand thoroughly to familiarise him with the procedure. The order of drawings trials and faces trials was randomised across subjects so that half received drawings first and half received faces first. The designated keys for decisions "same" and "different" were similarly counterbalanced. Within a block of trials the position of stimuli (LVF, RVF or bilateral) occurred randomlythus preventing the subject from anticipating the kind of stimulus arrangement.

Both the stimulus presentation and response recording were carried out using a Macintosh portable computer programmed automatically to record response times (RTs) and errors. The principal dependent variable was RT to correct decisions. Each block comprised 40 trials, half of which involved identical stimuli and half where the pairs were different. Subjects were clearly instructed that not only could they not anticipate where the stimuli would fall relative to the fixation point, but that the sequence of "same" and "different" pairs was equally unpredictable. They were encouraged to make fast and accurate responses.

\section{Results}

The RT data for correct responses are tabulated in table 2 . The results are also illustrated in figs 2 and 3 for the drawings stimuli and faces stimuli, respectively. The entire data were first analysed by a three-way analysis of variance (group $\times$ stimulus type $\times$ visual field).

Table 1: Brief case histories of the Capgras group and the control group

\begin{tabular}{|c|c|}
\hline Capgras Group & Control Group \\
\hline $\begin{array}{l}\text { Patient 1: Unmarried male aged } 36 \text { years who was a university } \\
\text { graduate (geology) working as a shopowner in Cretè. Family } \\
\text { history of both psychotic and affective disorders. His illness } \\
\text { began in } 1989 \text { with symptoms of suspiciousness and auditory } \\
\text { hallucinations. He claimed his father was an impostor and } \\
\text { thought his sister someone else who looked like her. } \\
\text { Diagnosis: delusional (paranoid disorder } 297 \cdot 10 \text { (DMS-III-R } \\
\text { Criteria, Axis 1). } \\
\text { Treatment: trifluoperazine ( } 10 \mathrm{mg} / \text { day). }\end{array}$ & $\begin{array}{l}\text { Patient 1: Unmarried } 32 \text { year old male who was formerly a } \\
\text { school teacher (mathematics). Family history of affective } \\
\text { disorders. First psychotic episode occurred in } 1989 \text {; including } \\
\text { persecutory ideas, not being masculine enough and being } \\
\text { unattractive to women. } \\
\text { Diagnosis: schizophrenia (paranoid type) psychosis } 297 \cdot 0 \\
\text { (DSM- III-R Criteria, Axis 1). } \\
\text { Treatment: haloperidol ( } 30 \mathrm{mg} \text { day) + promazine ( } 25 \mathrm{mg} \\
\text { nocte). }\end{array}$ \\
\hline $\begin{array}{l}\text { Patient 2: Unmarried male aged } 32 \text { years with a poor } \\
\text { employment record and a history of alcohol abuse. No family } \\
\text { history of psychosis. In } 1990 \text { became withdrawn with } \\
\text { persecutory ideas and developed the notion that his mother } \\
\text { was not his real parent but a hostile substitute. Subsequently } \\
\text { he claimed his father had been replaced. } \\
\text { Diagnosis: undifferentiated schizophrenia } 295.9 \text { (DMS-III-R } \\
\text { Criteria, Axis 1). } \\
\text { Treatment: chlorprollsixene ( } 40 \mathrm{mg} / \text { day) + carbamazepine } \\
(600 \mathrm{mg} / \text { day). }\end{array}$ & $\begin{array}{l}\text { Patient 2: A } 32 \text { year old male, engaged to be married who in } \\
1986 \text { developed paranoid delusions that his mind was being } \\
\text { controlled by TV and that people were reading his thoughts. } \\
\text { He also complained of burning sensations in chest and } \\
\text { stomach caused by others. } \\
\text { Diagnosis: schizophrenia (paranoid type) } 29 \cdot 3 \text { (DSM-III-R } \\
\text { Criteria, Axis 1). } \\
\text { Treatment: trifluoperazine }(5 \mathrm{mg})+\text { chlorpromazine ( } 50 \mathrm{mg} \text { ) } \\
+ \text { antidepressants. }\end{array}$ \\
\hline $\begin{array}{l}\text { Patient 3: Unmarried epileptic male aged } 22 \text { years with a five } \\
\text { year history of withdrawal, emotional lability, and visual and } \\
\text { auditory hallucinations. Later he came to believe that his } \\
\text { mother had been substituted by a hostile person. SPECT } \\
\text { analysis revealed left sided parietal abnormalities. } \\
\text { Diagnosis: organic delusional syndrome } 293 \cdot 81 \text { (DSM-III-R } \\
\text { Criteria, Axis 1). } \\
\text { Treatment: trifluoperazine ( } 30 \mathrm{mg} / \text { day). }\end{array}$ & $\begin{array}{l}\text { Patient 3: A } 23 \text { year old unmarried male bakery worker with a } \\
\text { family history of psychiatric disorder. First psychotic episode } \\
\text { in } 1990 \text { with first rank symptoms. EEG record of mild } \\
\text { bilateral dysrhythmia. } \\
\text { Diagnosis: schizophrenia (paranoid type) } 295.3 \text { (DSM-III-R } \\
\text { Criteria, Axis 1). } \\
\text { Treatment: pimozide ( } 20 \mathrm{mg} / \text { day). }\end{array}$ \\
\hline
\end{tabular}


Figure 1 Illustrations of bilateral, $L V F$ and $R V F$ presentations of pairs of drawings or faces. Pairs of stimuli were exposed for 200 milliseconds on a computer screen and patients responded "same" or "different" by rapidly pressing one of two designated keys
Faces

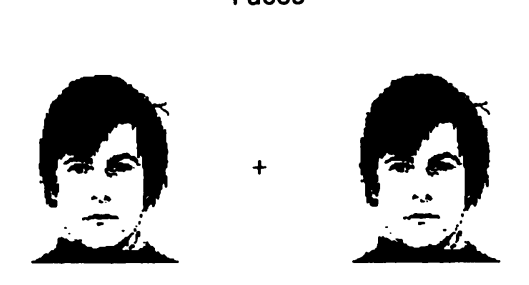

Objects

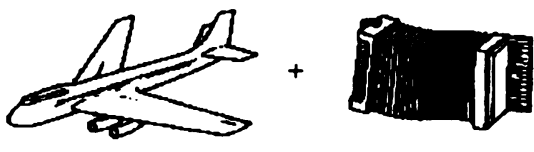

Bilateral

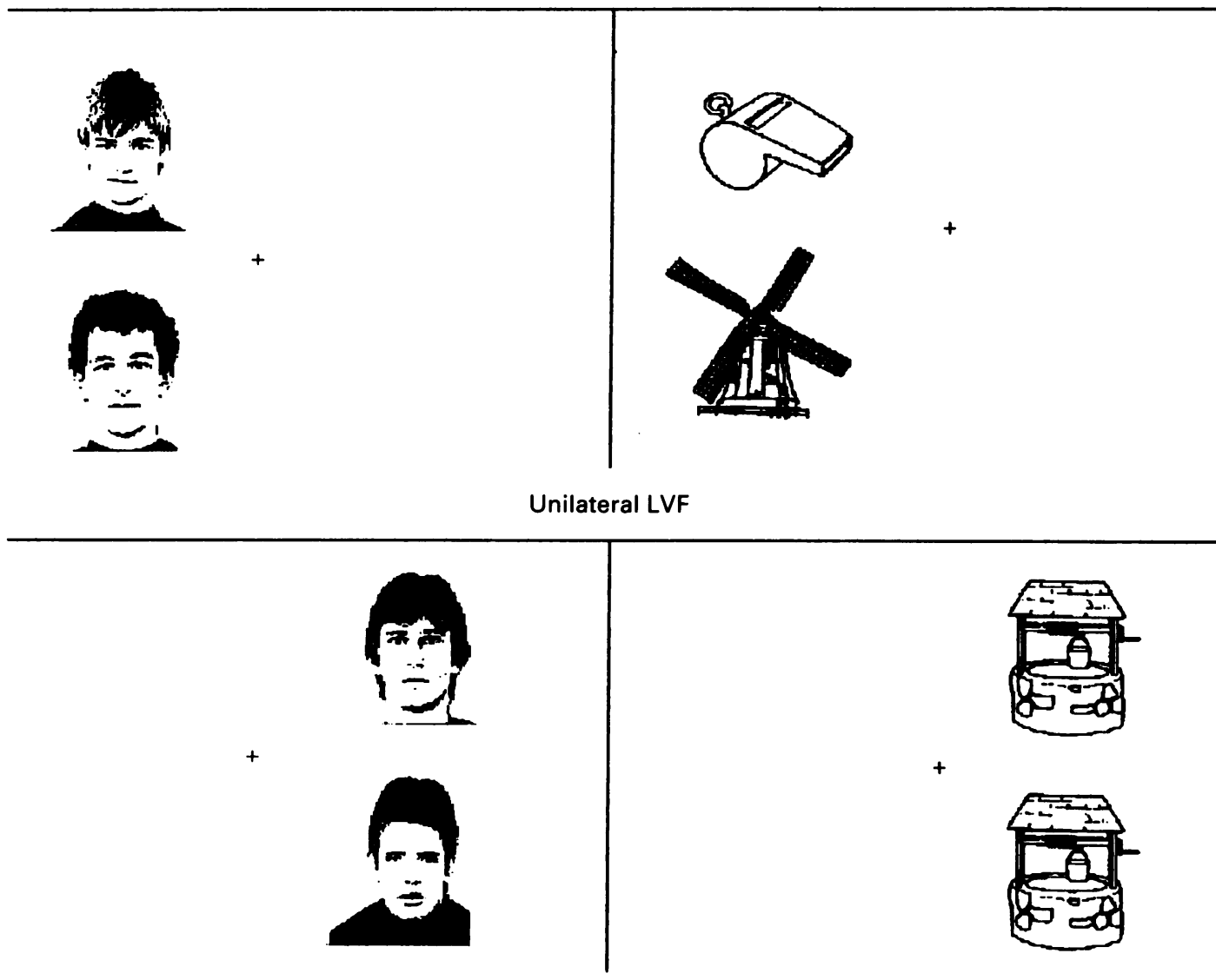

Unilateral RVF

This revealed significant main effects for stimulus types- $F(1,4)=36.94, p<0.01$ ); and for visual field- $F(2,8)=8 \cdot 14, p<0 \cdot 01$. It also showed interactions between stimulus type and visual field $-F(2,8)=5.33, p<0.05$; and among subject group, stimulus type and visual field-F $(2,8)=7 \cdot 82, \mathrm{p}<0.01$. In view of the latter, three-way interaction, simple main

Table 2 Response times (millisecs) for "same" and "different" decisions combined for both stimuli types (drawing and faces) and three presentation positions (LVF, RVF and bilateral).

\begin{tabular}{|c|c|c|c|c|c|c|}
\hline & \multicolumn{6}{|c|}{ Stimuli } \\
\hline & \multicolumn{3}{|c|}{ Drawings } & \multicolumn{3}{|l|}{ Faces } \\
\hline & $L V F$ & $R V F$ & Bilateral & $L V F$ & $R V F$ & Bilateral \\
\hline \multicolumn{7}{|l|}{ Control Group } \\
\hline 1 & 825 & 1025 & 770 & 1151 & 1266 & 950 \\
\hline 2 & 834 & 817 & 737 & 804 & 808 & 892 \\
\hline & 683 & 667 & 643 & 750 & 929 & 783 \\
\hline \multicolumn{7}{|l|}{ Capgras Group } \\
\hline 1 & 625 & 668 & 634 & 1041 & 970 & 709 \\
\hline 2 & 708 & 825 & 717 & 1150 & 1101 & 841 \\
\hline 3 & 717 & 633 & 679 & 1258 & 1109 & 900 \\
\hline
\end{tabular}

effects were calculated separately for trials using drawing and trials involving faces. These are reported within the separate sections below.

\section{Line drawings of objects}

Analysis by simple main effects revealed that there is no significant pattern of results for either the Capgras group or control group. Nor is there any obvious left/right asymmetry. Two of the control group were similar in being faster with stimuli falling in the RVF but this was not true of the third subject. The Capgras group also lacked uniformity: two subjects (1 and 2) demonstrated an LVF advantage but for patient 3 the opposite trend was evident.

There is a slight difference between groups in RTs to bilaterally presented stimuli. Every member of the control group was fastest with bilateral presentation but, again, data from patient 3 prevents the Capgras group showing the same uniformity.

Faces

The data that were obtained using pairs of 
Figure 2 Mean reaction times for each patient in the control group and the Capgras group for matching pairs of line
drawings of objects drawings of objects
presented in LVF, RVF and bilaterally
Figure 3 Mean reaction times for each patient in the control group and the Capgras group for matching pairs of photographs of faces presented in LVF, RVF and bilaterally
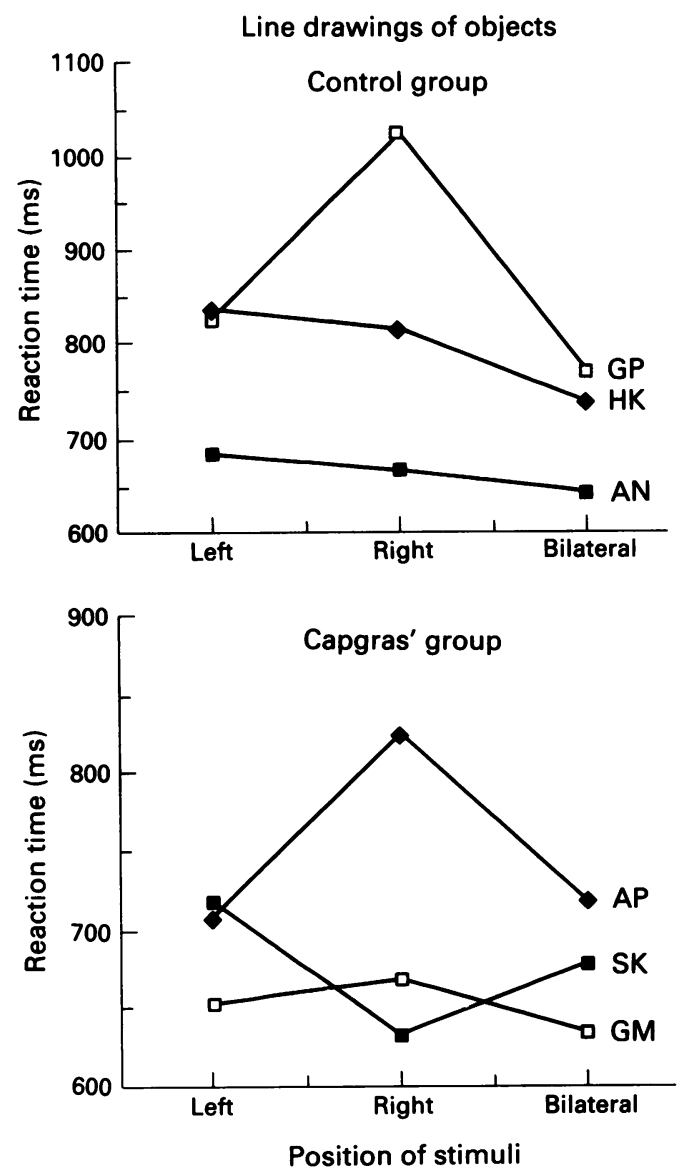

Discussion

The data from three experimental and three matched controls differ significantly only when stimuli were faces. When line drawing of objects were target stimuli the only notable pattern was that the control group were all faster at responding to bilaterally-presented stimuli compared with unilateral stimuli. There was no difference for either group between presentations in the left and right visual fields.

For face stimuli the most striking finding was the reversal in normal asymmetry for the Capgras delusion group. The control group all demonstrated the usual LVF advantage. The Capgras group also revealed a marked advantage in latency for responding to bilateral presentations.

The first observation is consistent with Cutting's ${ }^{16}$ hypothesis that the Capgras delusion may derive from some undefined impairment to the right hemisphere. He argues that the delusion is caused by damage to a system that recognises the uniqueness of a person. This fails to acknowledge the selectivity of the disorder, which applies to only certain people usually, but not always, emotionally close to the patient. ${ }^{20}$ It also implies that the disorder may apply to episodic memory for other types of sensory input but it is known that most, if not all, patients with the Capgras delusion only report that people have been substituted. Those who believe other things to have been substituted may be likened to prosopagnosia patients who display agnosia for certain objects as well as faces. ${ }^{21}$ As such, the attendant disorders may be considered to be incidental: they may occur because cerebral lesions are unlikely to neatly affect only a single input module. Equally, reduplicative paramnesia for faces and places are known to dissociate. ${ }^{22}$ Thus our data, while consistent with the view that in Capgras delusion there is some disorder in the face processing centres of the right hemisphere, do not necessarily support the details of Cutting's hypothesis. They do serve to implicate the right hemisphere which is also congruent with a meta-analysis of pathological observations by Feinberg and Shapiro. ${ }^{23}$ They found that a clear majority of Capgras patients in a sample of 26 showed bilateral or unilateral right hemisphere abnormalities. A similar asymmetry was found in a sample of 96 reduplicative paramnesia cases. 
Our data, however, pose as many problems for Cutting's ideas as they provide support for it. The three control patients, each diagnosed as schizophrenic, revealed a perfectly normal cerebral asymmetry for face recognition which Cutting's theory would not predict. Moreover, results with object stimuli failed to reflect Kosslyn's $^{17}$ speculation that the left hemisphere is specialised to recognise categories rather than individual examples of a category. According to this approach a RVF/left hemisphere advantage could have been expected in determining whether two objects (that is, two different categories) are the same or different. The data did not bear this out.

The fact that all three Capgras patients responded fastest to faces presented bilaterally, however, is not consistent with an elementary analysis of Joseph's ${ }^{8}$ position. A logical initial prediction from his view that the delusion occurs because there is some impediment to the cross-hemisphere integration of facial representations is that any such difficulty should be reflected in slower responses to bilateral stimuli. Clearly, this did not happen. Even ignoring the bilateral stimuli advantage for Capgras subjects, their mean response time for these trials $(816 \mathrm{~ms})$ is essentially identical to that produced by the control group $(808 \mathrm{~ms})$. Thus the present data are consistent with Joseph's hypothesis only if the dysfunction is present at more distal levels of association cortex involved in higher level cognitive information processing.

Our study serves to underline the likely advantages to be derived from adopting a cognitive neuropsychiatric approach to the study of the Capgras delusion. In particular it illustrates that a fairly simple experimental paradigm can yield data that may help to distinguish the competing accounts of this disorder. ${ }^{152526}$ Accordingly, further efforts aimed at examining in more detail the role of impairment in the right hemisphere in the aetiology of the Capgras delusion are warranted and should be encouraged. However, the possibility of left hemisphere ${ }^{9}$ or bilateral involvement ${ }^{8}$ still cannot be dismissed at this stage. The fact that the most recent results indicate that in some respects brain pathology in schizophrenics is more evident in the right compared with the left hemisphere, ${ }^{24}$ gives some general and indirect support to our findings. It is, however, unlikely that schizophrenia can be localised to one side or one part of the brain, nor can one anticipate that even a relatively simple symptom such as the Capgras delusion will eventually be localised to one area.

The work described in this paper was supported by a NATO Pauw, George Christodoulou and Anthony Joseph.

1 Capgras J, Reboul-Lachaux J. L'illusion des 'sosies' dans une delire systematise chronique. Bulletin de la Societe Clinique de Medecine Mentale 1923;2:6-16.

2 Christodoulou GN. The syndrome of doubles. Athens: Associate Professorship Thesis, University of Athens, 1975.

3 Berson RJ. Capgras' Syndrome. Am f Psychiatry 1983; 140:969-78.

4 Capgras J, Carrette P. L'illusion des sosies et complex d'Oedipe. Annals de Medical Psychologie 1924;82:48-68.

5 Todd J. The syndrome of Capgras. Psychiatry Quar 1957;31:250-65.

6 Enoch MD, Trethowan W. Uncommon psychiatric syndromes (3rd ed). Oxford: Butterworth-Heinemann, 1991.

7 Christodoulou GN, Malliaza-Loulakaki S. Delusional misidentification syndromes and cerebral dysrhythmia. Psychiatria Clinica 1981;14:245-51.

8 Joseph AB. Focal central nervous system abnormalities in patients with misidentification syndrome. Bibliotheca Psypatients with misidentifica
chiatrica $1986 ; 164: 68-79$.

9 Ardila A, Rosseli M. Temporal lobe involvement in Capgras' Syndrome. Int $\mathcal{F}$ Neurosci 1988;43:219-24.

10 MacCallum WAG. Capgras' Syndrome with an organic basis. Br f Psychiatry 1973;123:639- 42 .

11 Daniel DG, Swallows A, Wolff F. Capgras delusion and seizures in association with therapeutic dosages of disulfiram. Southern Med f 1987;80:1577-9.

12 Lewis SW. Brain imaging in a case of Capgras' Syndrome. Br f Psychiatry 1987;150:117-121.

13 Christodoulou GN. The syndrome of Capgras. $\mathrm{Br} f$ Psychiatry 1977;130:556-64.

14 Bidault E, Luaute JP, Tzavaras A. Prosopagnosia and the delusional misidentification syndromes. Bibliotheca Psychiatrica 1986;164:80-91.

15 Ellis HD, de Pauw KW. The cognitive neuropsychiatric origins of the Capgras delusion. In: David A, Cutting J, eds. The neuropsychology of schizophrenia. Hove: Erlbaum (in press)

16 Cutting J. The right cerebral hemisphere and psychiatric disorders. Oxford: Oxford University Press, 1990.

17 Kosslyn SM. Seeing and imagining in the cerebral hemispheres. Psychol Rev 1987;94:148-75.

18 Ellis HD. The role of the right hemisphere in face perception. In: Young AW, ed. Functions of the right hemisphere. London: Academic Press, 1983.

19 Rhodes G. Lateralized processes in face recognition. $\mathrm{Br} \mathcal{J}$ Psychol 1985;76:249-71.

20 Snodgrass JG, Vanderwart M. A standardized set of 260 pictures: Norms for name agreement, image agreement, picturiarity, and visual complexity 7 Experi Psychol: human learning and memory 1980;6:174-215.

21 Ellis HD. Recognising faces. Br f Psychol 1975;66:409-26. 22 Kapur N, Turner A, King C. Reduplicative paramnesia: possible anatomical and neuropsychological mechanisms. possible anatomical and neuropsychological mechar
$\mathcal{F}$ Neurol, Neurosurg Psychiatry 1988;51:579-81.

23 Feinberg TE, Shapiro RM. Misidentification-reduplicative in the right hemisphere. Neuropsychiatry, Neuropsychol
in in the right hemisphere. Neuropsychiar

24 Ron M. Schizophrenia and the brain: Where is it? $M R C$ News 1991;52:4-6.

25 Ellis HD, Young AW. Accounting for delusional misidentifications. Br $\mathcal{F}$ Psychiatry 1990;157:239-48.

26 Young AW, Ellis HD, Szulecka K, de Pauw KW. Face processing impairments and delusional misidentification. Behaviour Neurology 1990;3:153-68. 